\title{
Supervisors' opinion regarding the situation of postgraduate fellowship training in Gynaecology and Obstetrics of selected medical colleges in Bangladesh
}

\author{
Habiba Shamim Sultana', Iffat Ara ${ }^{2}$, Humayun Kabir Talukder ${ }^{3}$, AKM Asaduzzaman $^{4}$, Tahmina Nargis
}

\begin{abstract}
Background: Worldwide, the modernization of medical education is leading to the design and implementation of new postgraduate curricula. The necessity to reform postgraduate medical education has been recognized worldwide. Grounding in educational science and social accountability are raising issues.

Objective: To analyze the situation of the fellowship (FCPS, Part-II) training in Gynaecology \& Obstetrics of selected medical colleges in Bangladesh.

Methodology: This descriptive type of cross sectional study was conducted among 50 supervisors of Obstetrics \& Gynae dept. at selected medical colleges four in Dhaka city and four outside Dhaka. This study was carried out from January to December, 2014. The sampling technique was convenient sampling. In-depth interview of the supervisors was taken.

Results: During interview majority (60\%) of the supervisors told that the curriculum is followed in Obs \& Gynae Part 11 course which is made by BCPS is standard. About $80 \%$ supervisors told that the institution has well developed infrastructure, academic complex and OT complex for training and 70\% told that there are well organized investigation facilities and instruments available. Majority of the supervisors (80\%) told that supervisors and trainees ratio is proper. Majority of the supervisors $(75 \%)$ told that training is full time and residential. Majority of the supervisors $(95 \%)$ told that patient care services (outdoor, indoor and emergency) are satisfactory. About $80 \%$ supervisors told that they have not good library facilities with latest books and journals. Internet/website facilities are also not available in all libraries. Most of the supervisor $(80 \%)$ respondents believed that their hospital should have a mechanism for consultation, feedback and supervisory assessments system.

Conclusion: So significant room exists for improvement in the quality of fellowship training as indicated by the less than desirable proportion of trainees being satisfied with different aspects of training. Faculty members who constitute the cornerstone of educational process are pivotal to effect the desired improvements.
\end{abstract}

Key Words: Opinion, Training in Gynaecology and Obstetrics

\section{Introduction}

Post graduate training requirements have increased in modern times with focus on vast areas of management, team work, supervision and research. As a result, provision of quality education and training to junior doctors has remained a subject of great debate in the developed world. Besides, educational and environmental aspects, there is also a great debate on quality of life of junior doctors (mental health, social support, working hours) ${ }^{1}$.

\footnotetext{
${ }^{1}$ Junior Consultant, Gynae \& Obs, UHC, Gazaria, Munsiganj

${ }^{2}$ Professor, Gynae \& Obs, Dhaka Medical College

${ }^{3}$ Professor, Curriculum Development \& Evaluation, Centre for Medical Education, Dhaka

${ }^{4}$ Assoc. Prof., Curriculum Development \& Evaluation, Centre for Medical Education, Dhaka

${ }^{5}$ Asst. Prof., Education Science, Centre for Medical Education, Dhaka
}

Address of correspondence: Dr. Habiba Shamim Sultana

Junior Consultant, Gynae \& Obs, UHC, Gazaria, Munsiganj

E-mail: drhabibass@gmail.com
Post graduate training programs in the developed world are trying to adhere to a minimum standard of training, work hours and patient load. To ensure that these minimum standards are met, these programs are kept under tight check by a regulatory authority such as National Residency Control Commission (NRCC) in $\mathrm{UK}^{2}$. The aim is to provide an acceptable standard of active training to its residents (trainees)

Research Training and Monitoring Department (RTMD) of BCPS is engaged in improving the clinical skills of FCPS trainees and fellows of BCPS. Assuring and maintaining quality in clinical education is a complex process involving multiple agencies, institutions and individuals. Policy and practice agendas in education and health emphasize the need for continuous monitoring, review and evaluation of all processes from management systems through day to day teaching activities ${ }^{3}$.

Medical education is a dynamic and complex process. Individuals who receive their education from the best institutions are assumed to be more knowledgeable and to

Bangladesh Journal of Medical Education 2015;6(1):8-11. (C) 2015 Sultana et al., publisher and licensee Association for Medical Education. This is an Open Access article which permits unrestricted non-commercial use, provided the original work is properly cited. 
have higher intellectual potential to learn and accumulate firm-specific knowledge. The structure of postgraduate medical training is undergoing revision in many countries, notably in the United Kingdom prompting assessment of current practice in others, especially those based on British system. The scale of medical migration worldwide adds to the interest in review ${ }^{4}$.

The issue of sufficient resources and infrastructure for clinical training is a key area of focus for the Australian Medical Associations (AMA). Communication and social skills, professionalism and addressing patient management and social issues are aspects of medical education most neglected in teaching curriculums in third world countries ${ }^{5}$. The need for Obstetricians and Gynaecologists to keep up to date with new developments is particularly important after residency. Obstetricians and Gynaecologists learn about many newer treatment options after they have completed their specialty training ${ }^{6}$.

The necessity to reform postgraduate medical education (PGME) has been recognized worldwide. It is believed that better understanding can be summarized by situation analysis of fellowship training. It will show light on student expectation regarding training and will identify services quality gaps. This will help to identify areas of performance where improvement is required. This research will also provide a valuable insight regarding the quality of training imparted to the FCPS, part-II fellows of Gynaecology and Obstetrics of BCPS at its different identified / selected training sites. The MDGs are to reduce maternal and infant mortality rates in our country. If we want to achieve these goals, we need skilled Obstetricians along with others. Skilled Obstetrician can be produced only by ensuring quality clinical training on it. So the overall aim of the study is situation analysis of post graduate fellowship (FCPS, part-II) training in Gynaecology and Obstretrics in Bangladesh is a time felt need.

\section{Methods and materials}

The supervisors' opinion regarding the situation of postgraduate fellowship ( FCPS, Part 11) training in Gynaecology \& Obstetrics were taken through in-depth interview of 50 supervisor respondents among professors, associate professors and assistant professors of selected medical colleges. The questions were open according to the variables. Probing and follow-up questions were asked according to answers. Minutes of interview were recorded in written format and summarized at the end of the conversation. Similar and dissimilar opinion on a topic were grouped separately and transcribed to a common sentence for formulating result. Then the content was analyzed by the researcher and has been presented in a narrative form.

\section{Result}

During interview majority (60\%) of the supervisors told that the curriculum is followed in Obs \& Gynae Part 11 course which is made by BCPS is standard. During interview majority of the supervisor (80\%) told that the institution has well developed infrastructure, academic complex and OT complex for training. Majority of the supervisors (70\%) told that there are well organized investigation facilities and instruments available. Majority of the supervisors $(80 \%)$ told that the number of students, staffs and flow of patients are adequate. Supervisor and trainees ratio is proper. Majority of the supervisors (75\%) told that training is full time and residential. Duty hours per day is appropriate. They provide a fair and equitable distribution of workload among trainees. Majority of the supervisors (95\%) told that patient care services (outdoor, indoor and emergency) are satisfactory. Majority of the supervisors $(80 \%)$ told that they have not good library facilities with latest books and journals. Internet/website facilities are also not available in all libraries. According to the opinion of the majority (70\%) supervisor respondents that they provide adequate and appropriate supervision in all work situations. Most of the supervisor $(80 \%)$ respondents believed that their hospital should have a mechanism for consultation and feedback from trainees regarding their training and work. Majority of the supervisor $(80 \%)$ respondents told that the institution should have a sound and effective process for supervisory assessments system.

\section{Discussion}

During interview majority (60\%) of the supervisors told that the curriculum is followed in Obs \& Gynae Part 11 course which is made by BCPS is standard. They are trying to fulfill the objectives of the curriculum. The contents of the curriculum is adequate. The duration of the curriculum is also appropriate. This finding is consistent with other studies which were conducted in Australia and Pakistan in which $65 \%$ and $56 \%$ agreed with structured programme at their teaching hospital ${ }^{7}$. Some other supervisor $(10 \%)$ respondents added their idea about the curriculum as given below: "The present curriculum is knowledge based mainly. Skill based or competency based curriculum is needed." "Item wise contents of the curriculum is very much essential now."

During interview majority of the supervisor (80\%) told that the institution has well developed infrastructure, academic complex and OT complex for training. . Similar findings also seen in one study where they have well developed hospital buildings infrastructure, OT complex and clinical materials ${ }^{8}$. Majority of the supervisors $(70 \%)$ told that there are well organized investigation facilities and instruments available. Some supervisors $(30 \%)$ told that " there is shortage of instruments and the quality of the instruments are not updated." Majority of the supervisors $(80 \%)$ told that the number of students, staffs and flow of patients are adequate. Supervisor and trainees ratio is proper. Some supervisors (20\%) mentioned that "there is overloaded patients and the number of staffs is limited. Sometimes difficulties may arise to manage these patients and emergencies."

Majority of the supervisors (75\%) told that training is full time and residential. Duty hours per day is appropriate.

Bangladesh Journal of Medical Education 2015;6(1):8-11. 
They provide a fair and equitable distribution of workload among trainees. These findings are inconsistent to the findings of the AMA's survey report (2009) where they showed that only one-third (36\%) of respondents believed that their hospital provided them with a fair and equitable distribution of workload. Nearly half ( $47 \%$ ) believed that it did not ${ }^{9}$.

Majority of the supervisors (95\%) told that patient care services (outdoor, indoor and emergency) are satisfactory. Only a few supervisors (5\%) mentioned that "There is somewhere incoordination exist between these services". Majority of the supervisors $(80 \%)$ told that they have not good library facilities with latest books and journals. Internet/website facilities are also not available in all libraries. A group of supervisors (20\%) said that "They need modern library with all above facilities".

According to the opinion of the majority (70\%) supervisor respondents that they provide adequate and appropriate supervision in all work situations. They give them right decision when emergency and difficult situations arise. They guide the trainees to acquire research skills by giving assistance in dissertation. The immediate supervisor supervise that the entries in the log book are made soon after procedure/seminar/case presentation is completed and then certify it by signing the appropriate column. They ensure that the trainee is exposed to and is taught all aspects of the specialty available in the department. They recognize the deficiencies in training both theoretically and practically and appropriate steps be taken to overcome them.

Feedback is a vital component of medical education at all stages of the medical education continuum. It is essential that junior doctors can get access to feedback and appraisal processes relevant to their level of practice. Most of the supervisor $(80 \%)$ respondents believed that their hospital should have a mechanism for consultation and feedback from trainees regarding their training and work. This finding is inconsistent with other study findings in which $37 \%$ agreed that ${ }^{10}$. Majority of the supervisor $(80 \%)$ respondents told that the institution should have a sound and effective process for supervisory assessments system. In one study it was found that only $1 \%$ of respondents believed that their hospitals had any processes for supervisor's assessments ${ }^{10}$. BCPS has started to introduction of logbook during oral examination on random basis. Formation of training assessment group for interviewing trainees at six months interval to detect the lapse and gaps to identify any unmet facilities during training period. They also told that different groups are formed for assessments of the protocols of dissertations.

\section{Conclusion}

Bangladesh's public hospitals are central to the education and training of doctors. This study found that in order to achieve effective training, good quality supervisors, effective supervision adequate opportunity to experiential learning, conducive environment, good support system (hospital management, hospital staff, academic opportunities), personal attributes and reasonable workload are essential factors.

The training should be structured and well supervised. A group of trainees worked without honorium. There is no placement in the community. There is no way that the training is instructed, unsupervised and without monitoring. The service delivery unit mostly worked with services, less time for supervision, assessment and feedback given to the trainees. A separate unit of supervisors needed for supervision, assessment and monitoring of the training. Supervisors and trainees ratio is to be well balanced. Electronic logbook and electronic record system is now the time honored need. So that Bangladesh can maintains a world class medical education system and a highly-skilled medical workforce. This is the best interests of all Bangladeshis.

\section{References}

1. Hebert RS, Levin RB, Smith CG, MLS, Wright SM, 2003. A systematic review of resident research curricula. Acad. Med. 78: pp 61-68

2. Sadana R, D'Souza C, Hyder AA, Chowdhury AM , 2004. Importance of health research in South Asia. BMJ 328: pp 826-830

3. Aslam F, Qayyum MM, 2004. Catastrophic failures of public health. Lancet 363: p 1553

4. Biggs JSG, 2008. Postgraduate medical training in Pakistan: Observations and recommendations. $J$ Coll Physicians Surg Pak 18(1): pp 58-63

5. Singhal K, Ramakrishnan K, 2003. Training needs of international medical graduates seeking residency trainng: Evaluation of medical training in India and The United States. The Internet Journal of Family Practice 3 (1)

6. Smith GN, McNamara H, Bessette P, Allen VM, Ross S, Schulz J, et al. 2011. Resident research training objectives and requirements of the Association of Academic Professionals in Obstetrics and Gynaecology. JObstet Gynaecol Can 33(10): pp 1044-1046

7. Gill S, Levin A, Djurdjev O, Yoshida EM, 2001. Obstacles to residents' conducting research and predictors of publication. Acad Med 76: 477

8. Sathidevi VK, Sivadas MG, 2013. SWOT analysis of medical education and training in government medical colleges, Kerala, India. International Journal of Scientific and Research Publication 3(3): pp 1-5

9. Australian Medical Association. AMA junior doctor training, education and supervision survey report of findings [Online]. 2009 [ cited on 2012 Aug 12 ${ }^{\text {th }}$ ]. Retrieved from URL: https//ama.com.au/system/files/ node/5202/AMA\% 20TES\%20Report-1.pdf on March 12,2011 .

Bangladesh Journal of Medical Education 2015;6(1):8-11. 
10. Khan AA, Shaikh S, Ahmed Z, Zafar M, Anjum MU, Tahir A, et al. 2014. Quality of postgrsduate medical training in public and private tertiary care hospitals of Karachi.J Postgrad Med Inst 28(1): pp13-18 